\title{
A antropologia urbana e os desafios da metrópole
}

José Guilherme Cantor Magnani

0 título é "A antropologia urbana e os desafios da metrópole" ${ }^{1}$, mas 0 primeiro desafio será encontrar o tom certo, pois estão presentes alunos que acabam de ingressar no curso de ciências sociais, alunos antigos, alguns que já fizeram disciplinas comigo - podem até imaginar o tema e andamento desta aula -, além de estudantes de pós-graduação e colegas professores. Trata-se, por conseguinte, de um público bastante heterogêneo, com expectativas diferentes, cabendo-me a tarefa de encontrar um fio condutor capaz de interessar a todos a respeito da antropologia e, em especial, da antropologia urbana.

$\mathrm{N}$ ada mais apropriado do que começar discutindo al gumas idéias bastante arraigadas, tanto no senso comum como no meio acadêmico, a respeito da antropologia. Assim, há quem pense que a antropologia recorta sempre, como tema de estudo, um objeto exótico, distante ou singularizado; já em termos de posição epistemológica, ela se caracterizaria pelo relativismo, com as conseqüências de uma supervalorização do discurso do nativo e ausência de quadros de interpretação e análise mais gerais e universalizantes. E quando se considera mais especialmente o trabalho do antropólogo às voltas com questões urbanas, pesa sobre ele um preconceito adicional, dessa feita partindo do interior da própria antropologia, ou seja, há uma espécie de discriminação doméstica. E o ponto de partida dessa visão é que a antropologia, em sua forma clássica, praticada no contexto das sociedades não ocidentais, desenvolveu uma reflexão própria a respeito de temas específicos como parentesco, mitologia,
1. Aula inaugural realizadaem 10 demarço de2003 naFFLCH/U SP. 
xamanismo, rituais que - esses sim - conformam um campo de reflexão reconhecido e legítimo no interior das ciências sociais.

A pergunta que se coloca diante disso é: onde entra a antropologia urbana nesse cenário? Será que o estudo das sociedades e da cultura ocidental não caberia a outros ramos das ciências sociais? Q ual a especificidade da chamada antropologia urbana? Antes de entrar nessa discussão, cabe um lembrete de ordem histórica: a antropologia urbana, apesar de muitas vezes ser pensada como um desenvolvimento tardio da própria antropologia, apresenta alguns antecedentes que foram até contemporâneos àqueles da antropologia clássica voltada para os chamados povos primitivos. 0 sociólogo R obert Ezra Park, da Escola de $\mathrm{C}$ hicago, refere-se a essa situação nos seguintes termos:

A té o presente, a antropologia, a ciência do homem, tem-se preocupado principalmente com o estudo dos povos primitivos. M as o homem civilizado é um objeto de investigação igualmente interessante, e ao mesmo tempo sua vida é mais aberta à observação e ao estudo. A vida e a cultura urbanas são maisvariadas, sutis e complicadas, mas os motivos fundamentais são os mesmos nos dois casos. O s mesmos pacientes métodos de observação despendidos por antropólogos tais como Boas e Lowie no estudo da vida e maneiras do índio norte-americano deveriam ser empregados ainda com maior sucesso na investigação dos costumes, crenças, práticas sociaise concepções gerais de vida que prevalecem em L Little Italy, ou no baixo N orth Side de Chicago, ou no registro dos folkways mais sofisticados doshabitantes de $\mathrm{G}$ reenwichV illage e da vizinhança de W ashington Square em $\mathrm{N}$ ova York (Velho, 1987, p. 28).

Essa citação é de 1915 e, só para estabelecer um ponto de comparação, cabe lembrar que $0 \mathrm{~s}$ argonautas do Paáfico ocidental, de M alinowski, foi publicado em 1922. M uitos pesquisadores - que U If $\mathrm{H}$ annerz (1986) denomina de os "etnógrafos de Chicago" - seguiram essa sugestão e é bem conhecida sua produção sobre questões tipicamente urbanas nessa e em outras cidades norte-americanas, com repercussões mais am plas, até mesmo entre nós, como os famosos estudos de comunidade desenvolvidos na Escola Livre de Sociologia e Política e na então Faculdade de Filosofia, C iências e Letras (FFCL) da U SP, no final dos anos de 1940.

N o entanto, em todo estereótipo há sempre uma pista a seguir, assim como o senso comum, se elude algo, também alude a alguma coisa. Há, certamente, um perigo a identificar. Ao tomar como objeto do seu estudo as sociedades chamadas complexas, a antropologia urbana não deixa de ser antropologia, de forma que deve encarar um desafio: manter-se fiel ao patrimônio teórico e metodológico da disciplina, ao mesmo tempo em que é obrigada a traba- 
Ihar com outro tipo de recorte. E aqui está o problema, que é o de tentar reproduzir, principalmente no cenário das grandes metrópoles, aquelas condições tidas como clássicas na pesquisa antropológica: a dimensão da aldeia, da comunidade, do pequeno grupo. C abe notar que, se tais condições já não se aplicam nem mesmo nas próprias pesquisas da etnologia indígena, continuam presentes, no imaginário, como as características ideais da abordagem etnográfica. $\mathrm{N}$ o livro $\mathrm{N}$ a metrópole: textos de antropologia urbana (M agnani e Torres, 2000), denominei essa transposição de "a tentação da aldeia" , ou seja, a tentativa de reproduzir, no contexto bastante diversificado e heterogêneo das metrópoles, aquele lugar ideal onde supostamente se poderia aplicar, com mais acerto, o método etnográfico.

E aqui entramos nos desafios propriamente ditos da antropologia urbana, anunciados no título desta aula, aos quais podemos nos aproximar na forma de uma hipótese.

Proponho a hipótese de que a antropologia tem uma contribuição específica para a compreensão do fenômeno urbano, mais especificamente para a pesquisa da dinâmica cultural e das formas de sociabilidade nas grandes cidades contemporâneas e que, para cumprir esse objetivo, tem à sua disposição um legado teórico-metodológico que, não obstante as inúmeras releituras e revisões, constitui um repertório capaz de dotá-la dos instrumentos necessários para enfrentar novos objetos de estudo e questões mais atuais. 0 método etnográfico faz parte desse legado e um dos desafios é como aplicar essa abordagem à escala da metrópole sem cair na "tentação da aldeia" .

Para introduzir essa questão é preciso esclarecer o que é o método etnográfico. Inicialmente, cabe mostrar o que ele não é, e, nesse campo, não são poucos os mal-entendidos: às vezes, é confundido com o detalhismo, com a busca obsessiva dos pormenores na descrição das situações de campo; em outras, é identificado com a atitude de vestir a camisa ou ser o porta-voz da população estudada, sobretudo quando esta é caracterizada como grupo excluído ou uma minoria; em algumas ocasiões, é identificado com a reprodução do discurso nativo, por meio da transcrição de trechos de entrevistas nos quais, para melhor efeito de verossimilhança, são cuidadosamente preservados alguns erros de concordância ou sintaxe. Finalmente, para citar mais alguns desvios, o método etnográfico é visto como um esforço em transmitir o ponto de vista do nativo em sua autenticidade não contaminada com visões externas, ou ainda é identificado com o trabal ho de campo em geral ou como o conjunto das técnicas e métodos para fazer a pesquisa.

$M$ as então 0 que caracterizaria a etnografia? Podemos recorrer a alguns autores para tentar cercar essa questão. C lifford $\mathrm{G}$ eertz, numa passagem bastante conhecida, afirma que 
2. 0 que distingue a descrição densa de uma superficial éque estadescreve 0 ato de piscar como uma" rápida contração das pálpebras", enquanto a primeira distingue as diferentes estruturas significantes envolvidos nesse ato: pode ser um mero tique nervoso, um sinal decumplicidade, umaforma de comunicação, uma imitação etc.
[...] segundo a opinião dos livros- textos, praticar a etnografia é estabelecer relações, selecionar informantes, transcrever textos, levantar genealogias, mapear campos, manter um diário e assim por diante. M asnão são estas coisas, astécnicas e os processos determinados, que definem o empreendimento. 0 que o define é um tipo de esforço intelectual que ele representa: um risco elaborado para uma descrição densa (1978, p. 15).

$\mathrm{N}$ a continuação, Geertz vai exemplificar essa noção primeiro com 0 famoso caso das " piscadelas" ${ }^{2}$ e, em seguida, com um trecho de seu diário de campo, a interpretação de um conflito envolvendo pastores de carneiros, um comerciante judeu e a guarnição francesa no $\mathrm{M}$ arrocos.

$\mathrm{O}$ utro autor que ajuda a pensar a questão um tanto fugidia do que seja a prática etnográfica é M erleau-Ponty (1984). N o texto "D e M auss a C laude Lévi-Strauss", o autor afirma que "o emparelhamento da análise objetiva com 0 vivido talvez seja tarefa mais específica da antropologia, distinguindo-a de outras ciências sociais como a ciência econômica e a demografia". E prossegue, tirando uma conseqüência surpreendente:

Claro que não é possível, nem necessário, que o mesmo homem conheça por experiência todas as verdades de que fala. Basta que tenha, al gumas vezes e bem longamente, aprendido a deixar-se ensinar por uma outra cultura pois, doravante, possuí um novo órgão de conhecimento, voltou a se apoderar da região selvagem de si mesmo, que não é investida por sua própria cultura e por onde se comunica com as outras (Idem, pp. 199-200).

\section{E, finalmente, uma citação de Lévi-Strauss:}

É por uma razão muito profunda, que se prende à própria natureza da disciplina e ao caráter distintivo de seu objeto, que o antropólogo necessita da experiência do campo. Para ele, ela não é nem um objetivo de sua profissão, nem um remate de sua cultura, nem uma aprendizagem técnica. R epresenta um momento crucial de sua educação, antes do qual ele poderá possuir conhecimentos descontínuos que jamais formarão um todo, e após o qual, somente, estes conhecimentos se " prenderão" num conjunto orgânico e adquirirão um sentido que lhes fal tava anteriormente (1991, pp. 415-416).

C om base nas observações desses autores e de muitos outros antropólogos que sempre refletiram sobre seu trabalho de campo, é possível concluir, de maneira sintética, que a etnografia é uma forma especial de operar em que o pesquisador entra em contato com o universo dos pesquisados e compar- 
tilha seu horizonte, não para permanecer lá ou mesmo para captar e descrever a lógica de suas representações e visão de mundo, mas para, numa relação de troca, comparar suas próprias representações e teorias com as deles e assim tentar sair com um modelo novo de entendimento ou, ao menos, com uma pista nova, não prevista anteriormente.

Esse é um insight, uma forma de aproximação própria da abordagem etnográfica, que produz um conhecimento diferente do obtido por intermédio da aplicação e análise de, digamos, trezentos questionários ou de outras tantas entrevistas. Trata-se de um empreendimento que supõe outro tipo de investimento, um trabalho paciente e continuado ao cabo do qual e em algum momento, como mostrou Lévi-Strauss, os fragmentos se ordenam, perfazendo um significado até mesmo inesperado.

Com o propósito de tornar mais concreta e palpável essa perspectiva, vou trazer al guns exemplos; não serão os achados dos grandes mestres, nos textos clássicos, poisvocês terão todo o curso para descobri-los. Ficarei num âmbito mais doméstico, das minhas próprias pesquisas e das de meus alunos.

Q uando comecei a pesquisa que serviu de base para o doutorado, sobre modalidades de lazer, cultura popular e entretenimento na periferia de São Paulo, a pergunta com a qual fui a campo estava fundamentada em leituras de G ramsci, Foucault e Lévi-Strauss, sobre as relações entre ideologia e cultura. $\mathrm{N}$ o contexto dos estudos sobre os movimentos sociais urbanose a emergência de novos atores sociais, questionava-se se a cultura popular era fator de libertação ou se era mero reflexo da ideologia dominante. Assim, com base nessa discussão, saí a campo para realizar a pesquisa etnográfica e, bem, não vou aqui relatar essa pesqui sa ${ }^{3}$, mas posso dizer que fui com uma determinada questão e a resposta que obtive dos moradores, surpreendente, apontou para outra direção.

Em poucas palavras, a resposta foi a seguinte: não é o conteúdo da cultura popular, do entretenimento ou do lazer o que importa, mas os lugares onde são desfrutados, as relações que instauram, os contatos que propiciam. $M$ ais do que a suposta capacidade de liberação da cultura popular ou 0 poder da ideologia dominante sobre tradições culturais populares, surgia uma questão nova: a da própria existência de uma rica rede de lazer e entretenimento - e suas modalidades de fruição - na periferia urbana da cidade de São Paulo, paisagem habitualmente descrita como uma realidade cinzenta, indiferenciada (hoje se diria o território da exclusão, que é uma outra forma de reduzir as diferenças a um denominador comum, a um fator de homogeneização).

$\mathrm{N}$ a verdade, $\mathrm{O}$ olhar paciente do etnógrafo terminou apreendendo que há, sim, classificações, regras, diferenciações. A ssim, foi possível descobrir que,
3. 0 resultado da pesquisa encontra-se em M agnani (1998). 
naquele universo aparentemente monótono, havia uma extensa rede de lazer e diferenciações na forma de, por exemplo, praticá-lo: havia lazer de homens solteiros e casados, de mulheres e moças, de crianças e adultos; e também modalidades deffrutadas em casa e fora de casa, e neste último caso ainda era possivel distinguir "fora de casa, mas no pedaço".

Foi então que surgiu essa noção de pedaço, uma idéia nativa mas que terminou se tranfformando numa categoria mais geral na medida em que permitiu discutir e se integrar em outros esquemas conceituais. Em diálogo com a conhecida dicotomia "rua versus casa" de R oberto Da M atta (1979), essa noção revelou um outro domínio de relações: enquanto a casa é o domínio dos parentes e a rua, o dos estranhos, o pedaço evidencia outro plano, o dos "chegados" que, entre a casa e a rua, instaura um espaço de sociabilidade de outra ordem. Assim se desvelou um campo de interação em que as pessoas se encontram, criam novos laços, tratam das diferenças, alimentam, em suma, redes de sociabilidade numa paisagem aparentemente desprovida de sentido ou lida apenas na chave da pobreza ou exclusão.

Foi realmente um achado, não previsto pelas hipóteses do projeto original da pesquisa, pois surgiu no contato com os pesquisados, foi sugerido por eles, e só se transformou numa categoria de alcance mais geral quando contrastado com outro esquema conceitual e aplicado em novos contextos, diferentes daquele em que fora encontrado.

O utro exemplo vem da experiência de campo de um ex-aluno, hoje professor de antropologia na U niversidade Federal de São C arlos. Como ocorria com vários estudantes de graduação, na disciplina $\mathrm{A}$ Pesquisa de $\mathrm{C}$ ampo em A ntropologia, Luiz H enrique escolheu um botequim, para seu exercício etnográfico - sempre está presente a possibilidade de pôr em prática a observação participante... 0 tema era sobre o tempo livre e era preciso descobrir as concepções que os usuários tinham sobre lazer. A resposta obtida foi: "não, isto aqui não é lazer". M as, como? 0 pesquisador estava todo preparado com as teorias do lazer e do tempo livre e o informante dizia que aqueles momentos passados no botequim, no final da tarde, não constituíam lazer. Q ue eram, então? " $\mathrm{H}$ igiene mental", foi a inesperada resposta. Tal perspectiva não cabia, não se encaixava nas hipóteses; no entanto, ofereceu uma pista: aqueles momentos passados no botequim, em companhia de colegas após a jornada de trabalho, antes de voltar para casa, eram vividos como uma passagem entre 0 mundo do trabalho e o mundo doméstico. Então fazia sentido falar em higiene mental: aquelas pessoas eram trabal hadores que ainda traziam na roupa, no corpo, nos temas das conversas, as marcas dessa condição; a passagem pelo botequim era encarada como uma espécie de "descontaminação" antes da volta ao convívio com a família. 
Tudo bem, mas afinal o que eles consideravam lazer? "Lazer é quando eu me arrumo e vou com minha mulher a um barzinho ou, no fim de semana, quando vou passear na U SP" - evidentemente quando o campus era aberto para lazer da população, nos idos de 1989. De certa maneira, o entrevistado, ao mostrar de que forma usa seu tempo livre, deu uma pista para pensar as diferenças no modo de entendimento do lazer. $\mathrm{N}$ ão se trata de optar por uma visão mais autêntica ou verdadeira, mas estar atento para nuanças, modulações, princípios de classificação diferentes, a partir dos arranjos dos próprios atores. Essas pistas podem ser seguidas, aprofundadas e permitem enriquecer, no caso, uma compreensão mais ampla do que seja o lazer.

M as não vou me deter em exemplos antigos; tenho uma experiência mais recente, conhecida por alguns de vocês, pois já as relatei em algumas aulas. Trata-se de uma experiência até certo ponto inusitada para os moldes do trabaIho desenvolvido nesta faculdade. Há um ano mais ou menos fui convidado pelo professor Leland M cC leary, do D epartamento de Letras M odernas, para participar de uma pesquisa interdisciplinar juntamente com as áreas de lingüística e história, e o objetivo era um estudo sobre a comunidade surda de São Paulo e sua forma de comunicação, a língua brasileira de sinais - Libras. Leland já tinha ouvido falar do meu trabal ho a respeito de sociabilidade, de lazer, das categorias de pedaço, trajeto e achou que a antropologia poderia contribuir para a interdisciplinaridade, juntamente com os enfoques da lingüística, sobre as questões mais diretamente ligadas à língua, e da história, sobre narrativas e histórias de vida dos surdos.

Como entraria a antropologia? Talvez pelo lado da sociabilidade, detectando em que lugar eles se reúnem, como se comportam nos momentos de encontro. $\mathrm{N}$ a verdade não estava muito clara essa participação, mas mesmo assim insistiu. De minha parte, ainda um pouco desconfiado, aceitei: vamos ver o que se poderia fazer num campo tão diferente de minha área de atuação. M inha experiência com os surdos era como a da maioria das pessoas, a de alguma vez ter visto duas pessoas conversando por meio de sinais, sem prestar maior atenção - o olhar não treinado não vai além do que 0 senso comum registra.

Enfim, propus participar da equipe partindo daquilo que sabia fazer e que era tentar identificar os lugares de encontro e lazer dessas pessoas. Com alguns alunos definimos uma estratégia de pesquisa e fomos a campo fazer nosso estudo etnográfico, aproveitando o momento - era o mês de junho com suas festas características, o que não deixava de dar um toque especial para a escolha: em festa junina de surdo haveria música?

A primeira experiência foi numa festa de rua no bairro do Tatuapé, organizada pelaA ssociação para D eficientes daA udiovisão (A defav), uma organi- 
zação que trata não somente de surdos, mas também de deficientes visuais. A organização da festa não diferia muito das festas desse gênero na cidade, quando os vizinhosfecham a rua e a transformam momentaneamente em seu pedaço, mas que logo se dissolve, ao término da comemoração. Barraquinhas de comida e folguedos típicos, quadrilha, com a presença de surdos e também de parentes, amigos e professores ouvintes: enfim, foi uma festa do ciclo junino, parecida, em termos de estrutura, às muitas realizadas nessa época por instituições, escolas, grupos de vizinhos etc.

O utra festa a que compareci, duas semanas depois, foi realizada nas dependências do Instituto SantaTerezinha, no bairro da Saúde. Foi uma experiência diferente: entrei na festa e de repente me vi no meio de cerca de dois mil surdos - eu nunca tinha visto tantos surdos juntos - e ali eu é que era 0 estranho! N ão falava como eles, não entendia o que diziam, sentia-me caminhando por uma tribo cuja língua eu não conhecia, cujos costumes me eram alheios. Sequer sabia qual era a etiqueta, por exemplo: como é pedir desculpas, na língua de sinais, quando a gente esbarra em alguém? No início, essa dificuldade causou um certo constrangimento, mas logo comecei a circular no meio deles e a apreciar outras formas de contato e sociabilidade que, se eu não podia decodificar por meio daquela língua, porque eu não a dominava, podiam ser entendidas por meio de outros códigos.

Era a experiência etnográfica que todos querem no primeiro momento: entrar e mergulhar numa situação nova, deixando-se impregnar por aqueles estímulos e procurando familiarizar-se com todos aqueles significados. $\mathrm{N}$ um determinado momento subi numa arquibancada e, olhando de cima, o que presenciei foi um mar de mãos se agitando... Então me ocorreu que aquele espetáculo seria o equivalente ao barulho, se fosse uma festa de ouvintes. $\mathrm{N}$ esse momento ficou mais forte a impressão de estar num lugar em que eu era a minoria e, no entanto, não deixei de circular até encontrar um colega da equipe de pesquisa, um intérprete da língua de sinais, e um outro conhecido com os quais pude finalmente compartilhar al gumas sensações ali vividas.

Então veio a terceira experiência, que serviu de contraponto a essas duas. A nimado com as escolhas anteriores, resolvi ir a outra festa, a respeito da qual tinha ouvido falar numa das reuniões de trabalho da equipe. Era a Festa do C ow boy, programada na A ssociação dos Surdos de São Paulo, num sobrado no parque Jabaquara: comprei o ingresso e, uma vez lá dentro, consegui entrar em contato com uma pessoa que, por meio da leitura labial, entendeu minha pergunta e confirmou que, sim, ali era a festa.

Busquei um lugar, sentei-me esperando para ver o que acontecia, havia pouca gente ainda - todos eles conversando na sua língua de sinais - e eu lá, sentado numa cadeira, esperando alguma coisa acontecer... que, por favor, 
chegasse um intérprete ou algum conhecido, pois não estava entendendo nada e não podia circular porque 0 ambiente era pequeno. $C$ ada vez chegavam mais surdos, e eles, sim, se conheciam, formando grupinhos animados; divertiam-se muito, riam, comunicavam-se e eu absolutamente al heio, sem a menor chance não só de entender o que diziam, mas também de provocar algum contato: sentia-me fora de seu foco visual, era percebido num relance e imediatamente classificado como de fora daquele pedaço, impossibilitado de ser integrado por não dominar o código de reconhecimento e comunicação. A situação de desconforto foi num crescendo até que chegou um momento, depois de quase três horas de isolamento, de silêncio, de não entender, de não poder participar, em que resolvi ir embora, absolutamente frustrado com essa experiência, tão diferente das duas anteriores.

$\mathrm{M}$ as, chegando em casa e, pondo em prática uma das regras da pesquisa etnográfica que é rever e passar a limpo as anotações do caderno de campo, percebi que eles fizeram comigo o que normalmente os ouvintes fazem com eles o tempo todo: no contexto dos ouvintes são minoria absoluta, tratados como deficientes e eu pude vê-los numa situação inversa.

Foi uma pista interessante constatar que comportamento e interação dependiam do espaço em que ocorriam, e a primeira diferença era entre espaço público e privado. No âmbito do espaço doméstico, por exemplo, os surdos (quando filhos de pais ouvintes) são considerados deficientes auditivos e as famílias muitas vezes procuram esconder o fato, minimizálo, muitas tentam ensiná los a falar por meio do longo e trabalhoso processo de oralização, em sessões de fonoaudiologia. N o espaço público, ocorre uma mudança. Há instituições que continuam esse esforço de inclusão, de integrar o surdo no mundo dos ouvintes por meio do ensino, da profissionalização. N o entanto, nessas instituições - pedagógicas, religiosas, sociais, entre outras - , os surdos encontram-se e desenvolvem espaços próprios e mais intensos de contato e, principalmente, aprimoram seu principal elemento distintivo: a língua de sinais. O u seja, o espaço fora de casa não é homogêneo, permite gradações, apropriações seletivas.

A ssim, numa mancha de lazer eles podem estabelecer trocas mais amplas, não só com os surdos mas com os professores, funcionários, parentes, amigos; já no pedaço deles estão exercitando sua língua e cultura próprias e quem não é do pedaço não entra e se entrar tem de sair, porque essa é a regra básica num lugar onde 0 código, fundamental, separa os de dentro e os de fora. $N$ esses casos, diferentemente do âmbito do privado, a falta torna-se marca e eles se reconhecem como pessoas com uma forma diferente de entrar em contato. Então, se o espaço público é o lugar onde esse grupo adquire visibilidade como dotado de uma particular modalidade de comunicação e de cultura, 
não se trata do espaço público em geral - esse espaço é modulado e é preciso treinar o olhar para ver as diferentes formas de apropriação. D ependendo da forma em que se dá essa apropriação, a dinâmica torna-se diferente: a dinâmica deles no seu pedaço era uma, numa mancha do lazer era outra e, na festa de rua, outra.

Eram os mesmos personagens, mas, na verdade, a dinâmica era outra. Foi posśvel perceber que não se podia acoplar a pai sagem urbana a uma só modalidade de espaço público, mas era preciso distinguir as formas em que esse espaço público se apresentava e era trabalhado pelos usuários, o que redundava em diferentes dinâmicas urbanas e de sociabilidade. A ssim, a equipe começou a observar e estudar a presença e a participação dos surdos nas missas católicas, nos cultos evangélicos, em praças de alimentação de shopping centers, enfim, numa série de pontos de encontro. Essas pessoas, que estavam submersas numa sociedade majoritária de ouvintes e que eventualmente chamavam atenção no ônibus, nas ruas, quando em encontros de doisa dois, de repente adquirem não só visibilidade, mas também cidadania - com direito a exercer sua diferença.

Esse tema apresentava outras implicações de interesse para a análise antropológica, como a questão de se a surdez é uma falta, uma deficiência da capacidade auditiva com deter minadas conseqüências no plano da comunicação e socialização ou se, entendida como uma condição especial do aparato cognitivo, com ênfase em outra modalidade de simbolização, supõe uma forma peculiar de estruturação no plano da cultura. Trata-se de uma faceta das intrincadas relações entre natureza e cultura, e me veio à mente o conhecido texto de $\mathrm{R}$ obert H ertz, "A preeminência da mão direita: um estudo sobre a polaridade religiosa" ([1909] 1980).

D eixando de lado, por ora, essa linha de reflexão, é possível, com proveito, ficar no campo da antropologia urbana e pensar nas regularidades de uso do espaço e de comportamento por parte dos surdos: eles, no trato com a cidade, não se mostram dispersos, não estão submersos no caos urbano, mas se apropriam de forma tal que podem não só viver nela, como ainda reconhecer seus iguais e com eles estabelecer estratégias próprias de vida, de trabalho, de aprendizado, de encontros. E isso é possível porque a cidade, principalmente na escala da metrópole, possibilita que estabeleçam seus trajetos, estruturem seus circuitos, façam escolhas.

0 exemplo do estudo com os surdos permite relativizar certas noções generalizadoras como a deficiência, a exclusão, por exemplo, como fatores explicativos de comportamentos porque, olhando-se mais de perto a realidade designada por essas noções, é possível perceber as nuanças e as sutilezas de uma prática social que, para além dos fragmentos que se apresentam para 0 olhar não treinado, exibem algum tipo de regularidade e ordenamento. 
N o entanto, a etnografia urbana não se encerra na descrição de alguns lod privilegiados de sociabilidade, de encontro e de trocas, na cidade. G eorge M arcus (1991), no texto "I dentidades passadas, presentes e emergentes: requisitos para etnografias sobre a modernidade no final do século $X X$ no nível mundial", discute uma proposta que ele chama de etnografia modernista, para diferenciá-la do que denomina etnografia realista. N esse artigo, M arcus propõe problematizar o conceito de comunidade, tradicionalmente referida a uma localidade específica e a uma identidade determinada: é preciso dissolver as conotações de solidez e homogeneidade implicadas nessa relação, já que a formação de identidades depende de atividades desenvolvidas em muitos locais.

N essa mesma direção M arshall Sahlins(1997) - no artigo "O 'pessimismo sentimental' e a experiência etnográfica: porque a cultura não é um 'objeto' em via de extinção" - , com base em várias pesquisas, mostra o campo da etnografia no mundo contemporâneo e, em vez do enfoque tradicional, que reduz as sociedades do Pacífico, por exemplo, à insignificância de sua condição de insularidade, mostra que o mar não separa esses povos, ao contrário, ele os une, estabelece um contexto de troca muito mais amplo. A demais, as narrativas tradicionais de viagens, de retornos e outras evidenciam que essa não é uma situação nova. $M$ ais do que fixar a etnografia apenas no contexto mínimo da aldeia, que é onde o enfoque costumeiro faz a observação, a etnografia contemporânea deve levar em conta um fluxo muito mais amplo. Sahlins cita vários estudos sobre os habitantes de Tonga e de Samoa, por exemplo, e mostra que esses povos não podem ser tomados, no mundo globalizado, como comunidades separadas entre os que ficaram nas aldeias de origem, empobrecidos, levando a vida tradicional, e os que migraram em busca de trabalho nos grandes centros urbanos. 0 s samoanos que estão em $\mathrm{N}$ ovaYork e os que ficaram nas ilhas fazem parte de uma mesma cultura e é nesse contexto, complexo, que se deve buscar o entendimento do que muda e do que se mantém.

M as não é preciso ir muito longe para apreciar esse processo, podemos ficar com alguns exemplos domésticos - e, nesse sentido, quem aqui não conhece o M orro do Q uerosene $e^{4}$ onde, sob a direção de Tião C arvalho, o bumba-meu-boi de sotaque maranhense implantou-se e deu o tom ao bairro? M uitos alunos da graduação fizeram seus exercícios de etnografia sobre esse folguedo - mais recentemente M aurício Pascuet - e com base neles pode-se perceber que não se entende o que ocorre no M orro do Q uerosene só fazendo uma etnografia nessa local idade, sem levar em conta, por exemplo, São Luís do M aranhão. Há um contexto de trocas, um vai-e-vem constante e esse bumba-meu-boi não é nem maranhense nem paulistano.
4. Vila Pirajussara, no bairro do Butantã, São Paulo. 
5. Litoral norte do Espírito Santo, divisa com Bahia.
Q uem, também, já não ouviu falar dos índios pankararus, moradores da favela R eal Parque, no bai rro do M orumbi? C omo mostra Priscila M ata em sua pesquisa, não se pode considerá- los pobres favelados ou índios desaculturados, pois, sem perder os vínculos com seus parentes de Pernambuco, estabeleceram um eixo entre a aldeia e a metrópole. $E$, ao longo desse eixo, sustentam um fluxo constante de trocas, surgindo novas experiências, novos arranjos.

Q uem, também, já não ouviu falar do "forró universitário" (talvez até tenha freqüentado algum salão), criado no eixo Itaúnas / rua C ardeal A rcoverde, no bairro de Pinheiros? Como mostra D anielaA maral em sua pesquisa, tratase de uma forma de entretenimento desenvolvida por jovens de classe média em contato com elementos da cultura nordestina.

As trocas entre sertão e metrópole também foram estudadas por $\mathrm{R}$ osani $\mathrm{R}$ igamonte (2001), que inicialmente pesquisou o C entro deTradições $\mathrm{N}$ ordestinas no bairro do Limão e, para entender o que se passava nesse espaço, teve de ampliar o âmbito da etnografia até as pequenas cidades do interior baiano, destino obrigatório da cíclica revoada de nordestinos, por ocasião das festas juninas. A distância entre esses dois pólos, metrópole e sertão, não é preenchida apenas pelas lembranças, pela música, pela saudade, mas por um fluxo intenso e muito concreto de objetos, mercadorias, correspondência, dinheiro, sustentado por um sistema semiclandestino mas seguro - porque fundado em laços de lealdade - de transporte e comunicação. D iferentemente do que ocorria nos primeiros tempos do processo migratório, que significava uma ruptura entre o pólo de expulsão e os centros urbanos de chegada, com separação entre membros da família, agora esses pólos estão em contato permanente, são simultâneos e de suas trocas surgem permanentemente novos arranjos, estratégias e soluções.

São apenas três exemplos de pesquisas de alunos, escolhidas no campo das relações entre a cultura nordestina e o contexto da metrópole; que dizer de outros temas e recortes como o futebol de várzea, as modalidades de cultura e entretenimento de jovens em suas diversas cenas (hardcore, punk, straight-edge, góticos, hip-hop, rappers, entre outros), as formas de religiosidade (carismáticos, grupos gospel, neo-esotéricos, entre tantos outros), experiências comunitárias, $\mathrm{O} \mathrm{N} \mathrm{G} \mathrm{s,} \mathrm{esportes} \mathrm{radicais,} \mathrm{torcidas} \mathrm{organizadas,} \mathrm{moradores} \mathrm{de} \mathrm{rua,} \mathrm{propos-}$ tas de renovação urbana, enfim, um sem-número de objetos de estudo que, aparentemente singulares, limitados ou exóticos abrem pistas para se entender não só sua lógica, mas sua inserção na paisagem da cidade. D esde, é claro, que se saiba como fazer as perguntas pertinentes.

Tais são as possibilidades, entre outras, que se abrem para a antropologia urbana. E, em vez de uma reduplicação do discurso corrente sobre o decantado caos urbano, um olhar atento - que chamei, em outra ocasião, de olhar 
"de perto e de dentro" (M agnani, 2002) - vai captar arranjos, mecanismos e saídas surpreendentes dos atores sociais e que não são visíveis a um olhar meramente de fora. É dessa forma que a metrópole, na sua diversidade e na sua escala e também nos seus conflitos e problemas específicos, se torna inteligível, pois esse olhar parte das experiências daqueles que nela vivem, abrindo pistas para o entendimento de sua lógica e de sua inserção em contextos mais gerais. Esse é o toque da etnografia, na medida em que ela trabalha não apenas aqueles ar ranjos específicos, forjados pelos atores numa prática que é coletiva - seja no terreno de trabalho, do lazer, da religiosidade e outros - , mas também está atenta e leva em conta suas representações, de forma a elaborar um modelo explicativo mais abrangente.

Essa troca contínua faz da etnografia uma marca característica da produção antropológica, buscando modelos compreensivoscomo resultado de um trabaIho específico que transita entre a teoria dos nativos - porque eles lá têm a sua teoria, têm as suas explicações que orientam a sua prática e dão sentido a seu mundo - e as teorias e as explicações do pesquisador, porque ele também tem seu arcabouço teórico.A novidade, quando ocorre- edepende do investimento do trabalho e de alguns “imponderáveis" do próprio campo - éa descoberta de um modelo novo, ou ao menos de uma pista inesperada que leve a uma reflexão inovadora. Essa é a sua proposta que deixa longe, certamente, aquelas idéias do senso comum para as quais a antropologia está presa ao exotismo, ao estudo de caso, ao detalhe sem fim, ao ponto de vista limitado do nativo.

Essa perspectiva de trabal ho supõe, evidentemente, um treinamento. $N$ ão está pronta em manuais de pesquisa, mas surge como resultado de um investimento em muitas frentes - 0 conhecimento da bibliografia teórica de base, a leitura de etnografias clássicas e, imprescindível, a experiência direta de campo. No entanto, a formação do etnógrafo não significa um enclausuramento no interior de seus textos e métodos: é preciso estar aberto à reflexão feita em outros campos, e não só no âmbito de nosso curso, das ciências sociais, porém, deve incluir outros parceiros. M as começa em casa, lógico; 0 que 0 antropólogo faz em campo - escutar o outro, entrar em contato com suas representações, reconhecê-lo como interlocutor - deve ser feito aqui: só assim seu olhar estará devidamente treinado para a prática da etnografia, na aldeia, no campo, na metrópole. M uito obrigado.

Referências Bibliográficas

D A M ATTA, R oberto. (1979), C arnavais, malandros e heróis. R io de Janeiro, Z ahar.

GeERTZ, C lifford. (1978), Interpretação das culturas. R io de Janeiro, Z ahar.

H An ner Z, U If. (1986), Exploración de la ciudad. M éxico, Fondo de Cultura Económica. 
HeRTZ, R obert. ([1909]1980), "A preeminência da mão direita: um estudo sobre a polaridade religiosa”. R eligião e Sociedade, $6, R$ io de Janeiro.

LÉvi-St r au ss, Claude. (1991), A ntropologia estrutural. R io de Janeiro,Tempo Brasileiro.

M AGN AN I, J. Guilherme. (1998), F esta no pedaç: alltura popular e lazer na cidade. 2. ed., São Paulo, Hucitec.

. (2002), "D e perto e de dentro: notas para uma etnografia urbana”. R evista B rasileira de C iências Sociais, 17 (49), jun., São Paulo.

M AGNAN I, J. Guilherme \& T ORR ES, Lilian. (2000), N a metrópole: tex tos de antropologia urbana. São Paulo, Edusp/ Fapesp.

M ALIn ow Skı, B ronislaw. ([1922] 1978), A rgonautas do Paáfico oddental. São Paulo, A bril C ultural (coleção "O s Pensadores").

M arcus, George. (1991), "Identidades passadas, presentes e emergentes: requisitos para etnografias sobre a modernidade no final do século XX no nível mundial. $R$ evista de A ntropologia, 34, São Paulo.

Mer Leau-Ponty, M aurice. (1984), “D e M auss a C laude Lévi-Strauss”. In: Textos selecionados, São Paulo, A bril Cultural (coleção "O s Pensadores").

R IGAm onte, R osani. (2001), Sertanejos contemporâneos: entre a metrópole e o sertão. São Paulo, Humanitas/Fapesp.

Sahlins, M arshall. (1997), “O 'pessimismo sentimental' e a experiência etnográfica: por que a cultura não é um 'objeto' em via de extinção”. M ana, 3 (1 e 2), R io de Janeiro.

Velho, 0 távio (org.). (1987), 0 fenômeno urbano. R io de Janeiro, Guanabara.

\section{Resumo}

0 texto analisa a situação da disciplina antropologia urbana no campo das ciências sociais e sua contribuição para o estudo e a compreensão do fenômeno urbano, principalmente no caso das grandes metrópoles contemporâneas. 0 eixo da argumentação é 0 de que, para real izar essa tarefa, a antropologia urbana tem à sua disposição o método etnográfico, porém 0 desafio é aplicar essa abordagem sem cair na "tentação da aldeia", isto é, a de buscar na heterogênea realidade das grandes cidades as condições da aldeia - pequenos grupos, contextos limitados - supostamente identificadas com o enfoque etnográfico.Vários exemplos de pesquisas recentes sobre a cidade de São Paulo, realizados no N úcleo de Antropologia U rbana (N AU ) e no D epartamento de Antropologia da U SP são apresentados para mostrar as poten-

José Guilherme Cantor Magnani é professordoutor do D epartamento de Antropologia da U SP; coordenador do N AU e editor-responsá vel da R evista deA ntropologia da U SP. cialidades da aplicação de conceitos, técnicas e métodos desenvolvidos na antropologia e, em particular, na antropologia urbana, para o estudo de formas de sociabilidade e práticas culturais na escala da metrópole.

Palavras-chave: A ntropologia urbana; Etnografia; M etrópole; Pesquisa de campo.

\section{Abstract}

State of the art of urban anthropology as a subject in the field of social sciences and its contribution to the study and understanding of the urban phenomenon, mainly in the case of 
great contemporary metropolises. U rban anthropology has at its disposal the ethnographic method but the challenge is to apply thisapproach without falling into the'village temptation', i.e., that of looking at the heterogeneous reality of the big cities for the village conditions small groups, limited contexts- which are supposedly identified by the ethnographic approach. Various examples of recent researches on the city of São Paulo, undertaken in the U rban Anthropology N ucleus (N AU ) and in the D epartment of Anthropology of U SP, are presented to show the potentiality of the application of concepts, techniques and methods developed in anthropology, and in particular, in urban anthropology, for the study of forms of sociability and cultural practices on a metropolitan scale.

Key words: U rban anthropology; Ethnography; M etropolis; Field research. 